\title{
Evolution of the second-story city: the Minneapolis Skyway System
}

\section{Michael J Corbett}

HDR Engineering Inc., 701 Xenia Avenue South, Suite 600, Minneapolis, MN 55416, USA; email: michael.corbett@hdrinc.com

\section{Feng Xie $\uparrow$, David Levinson}

Department of Civil Engineering, University of Minnesota, 500 Pillsbury Drive SE, Minneapolis, MN 55455, USA; e-mail: xiex0055@umn.edu, dlevinson@umn.edu

Received 4 June 2007; in revised form 17 June 2008; published online 6 April 2009

\begin{abstract}
This research describes the growth of the Minneapolis Skyway network and aims to determine if the growth of the system has followed a predictable path. We hypothesize that the system expanded to the places in which it was valued the most. The point accessibility of each block lying within and adjacent to the connected system for each expansion year is calculated and used to predict the expansion of the Skyway System. In order to determine how often the expansion connected the blocks with higher accessibility, a connection-choice logit model relating the probability of joining the network (in a given year) to accessibility measures and network size was employed. The results disclose that accessibility is a significant explanatory factor of network growth. In accordance with the findings from the logit model, a network-growth simulation model was then developed on the basis of the strongest-link assumption (ie for a link to be constructed, it must be ranked the highest in terms of increasing accessibility between the two blocks it connects). The results show that the simulation model performs well in predicting the sequence of skyway additions on the basis of the myopic strongest-link assumption. This suggests that-although various physical, economic, regulatory, and legal factors may have played a role-accessibility remains an important factor in predicting which links are connected during the growth of the Minneapolis Skyway network.
\end{abstract}

\section{Introduction}

At least sixteen cities in North America have notable skyway systems (covering over a dozen blocks) - that is, networks of above-grade connections between buildings that are often enclosed and climate controlled, and which link second-level corridors within buildings and various activity hubs, such as shops and offices (Byers, 1998; Robertson, 1994). Such links allow for more efficient movement of pedestrians (and thus increased accessibility) while protecting them from inclement weather and the hazards of vehicular traffic below. Unlike sidewalks, skyways are usually owned by private organizations, and connect private buildings to one another.

The Minneapolis Skyway System began in 1962 as a modest effort to provide greater access to the first mixed-use building downtown. It featured commercial office space, a hotel, indoor parking, and retail and restaurant space both on the street level and on the second level. Over the next four decades a system of skyway links emerged, resulting in a network that connected over seventy continuous blocks. Throughout the growth and development of the system, the City of Minneapolis laid out several visions of a skyway system connecting most of the blocks downtown (Jacob, 1984; Kaufman, $1985)^{(1)}$. Despite this, the evolution of the network did not always align with what planners had envisioned, leading some to criticize the seemingly haphazard growth (Byers, 1998). This paper attempts to determine if the growth of the system followed

(1) These findings are based on an examination of the Minneapolis Skyway system from Skyway News, from its initial publication in 1984 to 2004.

$\uparrow$ Corresponding author. 
a predictable path. One might hypothesize that the system expanded to the places in which it was valued the most. This may be reflected in the assessed worth of the surrounding unconnected blocks, or perhaps in the number of people (ie jobs). In this paper the point accessibility of each block lying within and adjacent to the connected system is calculated for each expansion year in order to determine if this measure can be used to predict the growth of the skyway system.

The remainder of the paper is organized as follows. First the evolution of the skyway system is described, and the motivation of skyway construction is examined. The next section briefly describes the theory and definition of accessibility, and the measurement criteria used in this study. The fifth section lays out the methodology used to predict the growth of the skyway network on the basis of accessibility measures. Section 6 presents the results and analysis, followed by conclusions and recommendations.

\section{Evolution of the Skyway System}

After the Second World War, suburbanization of housing, retail, and employment removed people from the downtown areas in many cities throughout the United States. The central business districts (CBDs) declined in importance, a trend that was exacerbated by the emergence of suburban shopping centers. In Minneapolis developer Les Park became concerned about this trend and felt that the CBD would need to compete with the suburbs to remain viable. He proposed a covered Plaza raised $4.25 \mathrm{~m}$ (14 feet) in the air over Nicollet Avenue, featuring an array of shops and restaurants. It would link buildings to parking ramps with skyway bridges.

The idea met with both enthusiasm and criticism. Some business leaders worried that the plaza-level establishments would put the street-level stores out of business. The plaza plan was dropped in favor of the present day outdoor transit mall on Nicollet in 1959, but Park was undeterred and commissioned Ed Baker to develop the Northstar Center (Byers, 1998; Kaufman, 1985). When it opened in 1962 it was the first mixed-use building in the city, featuring commercial office space, a hotel, indoor parking, and an array of retail and restaurant establishments on both the street and second levels (Byers, 1998). It also featured the city's first skyway bridge, connecting it with the Northwestern National Bank across Marquette Avenue. The next year a connection to the Roanoke Building over 7th Street was also completed. The original intent of these connections, made possible by collaboration between the Minneapolis City Planning department and local business leaders, was to make the financial district "more convenient for business people and clients to traverse" (Jacob, 1984, page 5).

The Northstar Center quickly became popular. Not surprisingly, downtown business leaders began to realize the potential that such developments had to offer, and some sought to cash in on it (Byers, 1998; Kaufman, 1985). In 1969 three skyways were added to the system. One skyway linking the Radisson Hotel to the Raddison Mart and parking was built over 7th Street. Another skyway spanned 6th Street between the FirstStar Bank (Northstar Center) and the Rand Tower, connecting four blocks of the financial district. The fifth skyway connected Dayton's Department Store with the LaSalle court over 8th Street. This was the first skyway to connect establishments in the retail core (Byers, 1998; Kaufman, 1985).

Perhaps the most significantly early addition to the Skyway System occurred when the IDS Center opened its doors in 1973. The block-sized, mixed-use complex featured four skyways that connected adjacent blocks in each direction. More importantly, the skyway over Nicollet Mall connected the financial district with the retail core, thereby establishing itself as the center of the system. It quickly became a new landmark for the city and captured the imagination of city dwellers and additional business leaders regarding what skyways could do for the downtown area (Byers, 1998; Kaufman, 1985). 


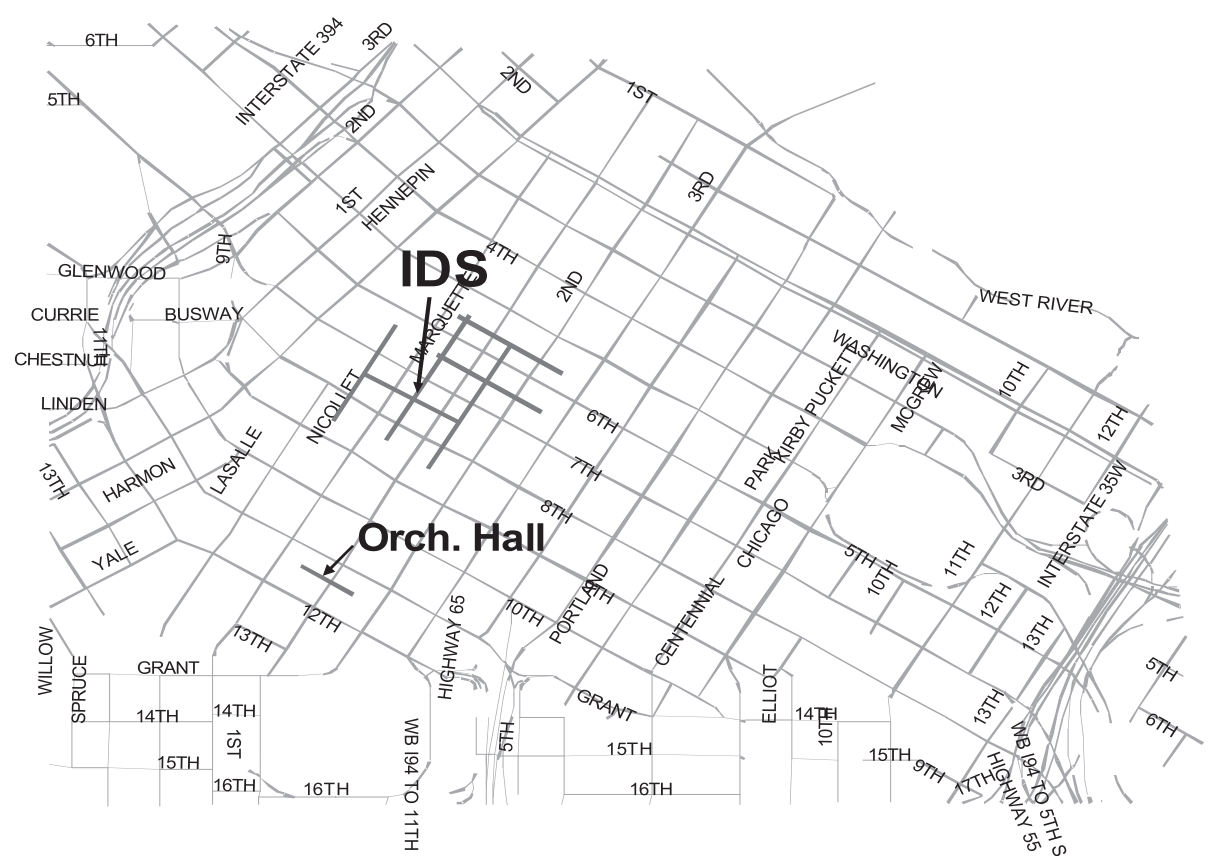

Figure 1. The Skyway network in downtown Minneapolis, 1975. IDS: the IDS Center, the tallest building in Minneapolis.

By 1975 thirteen blocks within the retail and financial core of the downtown area were connected by the Skyway System (figure 1). From 1975 to 1985 the system grew at a rapid pace. Much of the development occurred at several sites on the fringes of the CBD (Byers, 1998). On the eastern edge of the downtown area, the Hennepin County Medical Center (HCMC) connected their buildings together, but the HCMC was too far east to connect to the rest of the system. Substantial growth occurred in the Gateway district, just north of the CBD, linking office buildings and high-rise apartments together. Additional skyways linked the Government Center to areas south and east, including a municipal parking ramp, the Lutheran Brotherhood Building, and Centre Village. The new Piper Jaffray Building linked itself and the Energy Center to the main system near the financial core, and City Center, a shopping and entertainment complex completed in 1983, connected two additional blocks to the retail core (figure 2).

Most of the skyways in Minneapolis have been built through cooperation between private businesses and city government. All of the links in the early system were privately owned; thus operating hours depended upon decisions made by the building owners on each side of a skyway connection. This created problems, especially in the evening hours when some workers and shoppers were not able to return to their cars the same way they came in. There were also concerns about skyway bridge standards and security. As the system evolved so did its governance. In 1980 the Minneapolis Downtown Council created the Skyway Advisory Committee ${ }^{(2)}$ (SAC) to set guidelines

(2) The committee consisted of seventeen members who owned or occupied properties by the skyways, plus six nonvoting members, including representatives from the City Coordinators Office, Department of Public Works, City Planning Department, City Attorneys Office, Minneapolis Community Development Agency, and the Department of Inspections (source: memo prepared by Downtown Skyway Advisory Committee, 1993, reference 90R-286). 


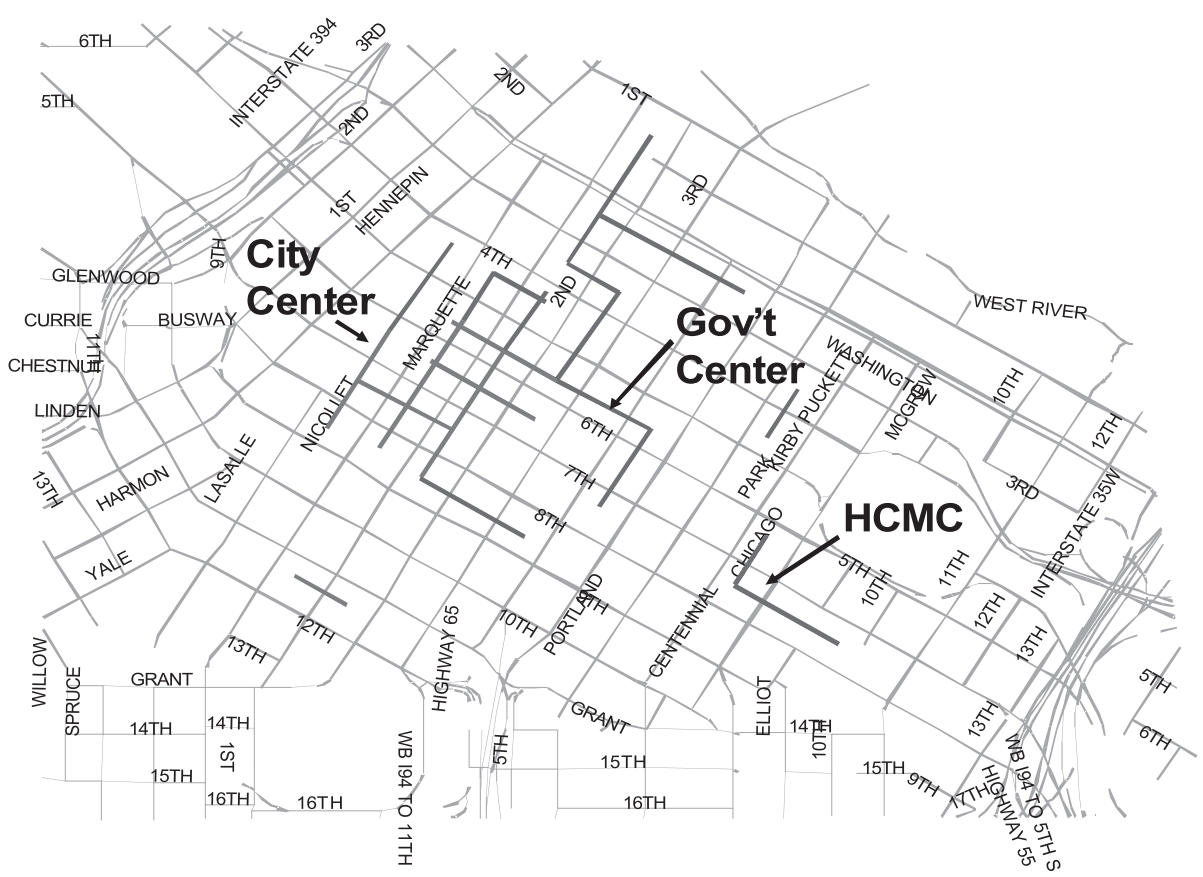

Figure 2. The Skyway network in downtown Minneapolis, 1985. HCMC: Hennekin County Medical Center.

for minimum bridge widths, heights, and spans, and to encourage owners to adopt uniform operating hours. The SAC provides design reviews and approvals for changes and additions to the skyway system, and serves in an advisory capacity to the Minneapolis City Council.(3)

From 1986 to 1995 much of the skyway expansion was led by the city of Minneapolis. The skyway system expanded along the South Mall to Orchestra Hall, and then onto the Convention Center. Significant skyway expansions were built to connect the Third Avenue parking ramps on the western edge of the downtown area with the retail and financial core of the system, in order to entice auto travelers to patronize them (Byers, 1998). There were other skyways built, two of which provided better connectivity between the retail and financial cores, but most of the construction was sponsored by the City of Minneapolis government and accounted for fifteen blocks that were added to the system (figure 3).

From 1996 to 2004 the pace of skyway construction slowed. A few blocks in the southwestern portion of the CBD were connected, owing to the new Target headquarters and adjacent store and St Thomas University's expansion efforts. The completion of the Block E retail/entertainment center also occurred (figure 4).

The evolution of the skyway system mirrors that of many transportation networks with its birth phase (1962 - 80), growth phase (1980-92), and mature phase (1992 to the

(3) Additional functions of the SAC serve to ensure accessibility by handling complaints and encouraging building developers to adhere to design requirements of the Americans with Disabilities Act, such as sideways-sliding power doors and appropriate ramp slopes to deal with elevation changes. Another important task includes setting standards for skyway system signage and navigational aids (Jacob, 1984). The main challenge for the SAC at present is acquiring funds to update the signage each time the system is expanded, according to one author's notes taken at the SAC Meeting on 18 March, 2004. 


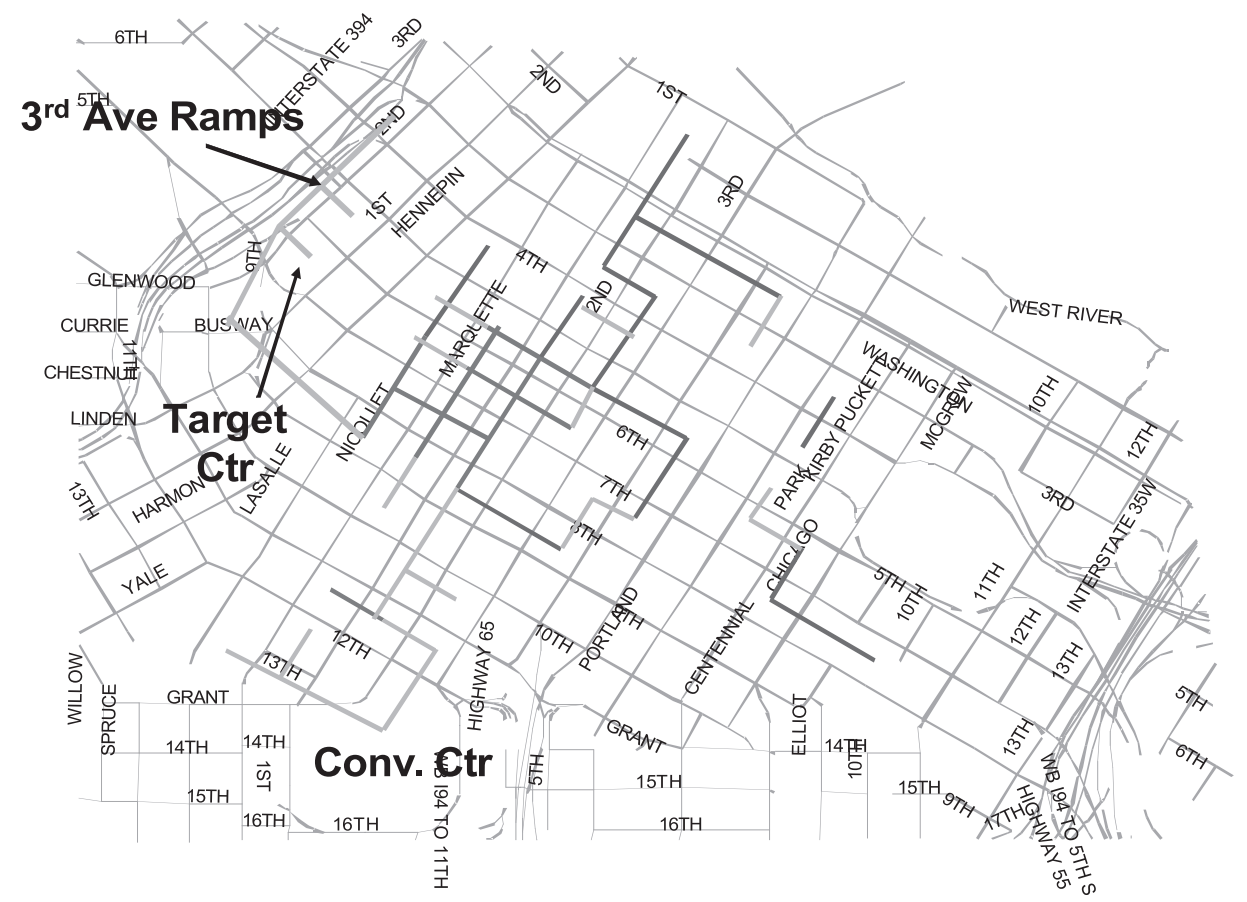

Figure 3. The Skyway network in downtown Minneapolis, 1995.

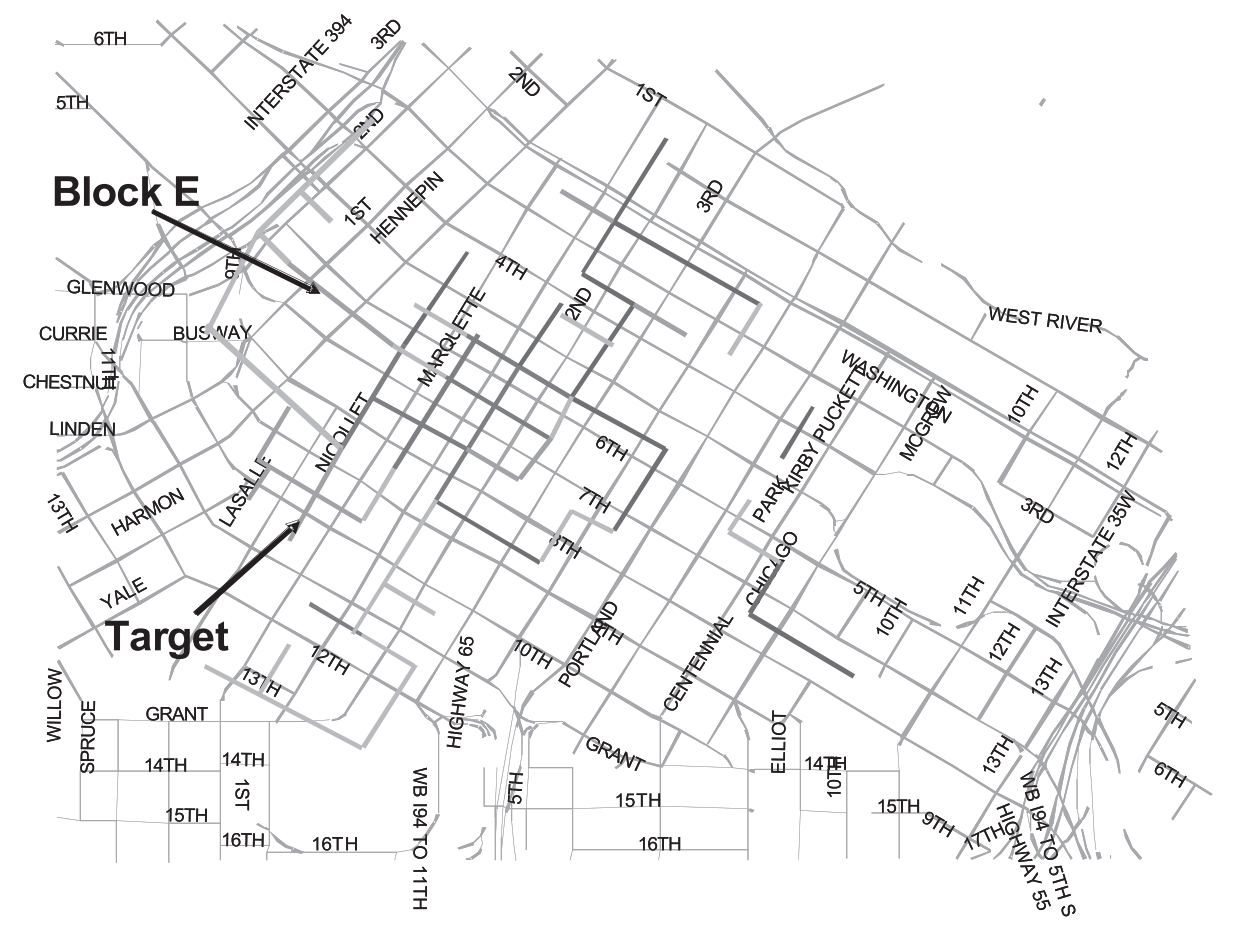

Figure 4. The Skyway network in downtown Minneapolis, 2004. 


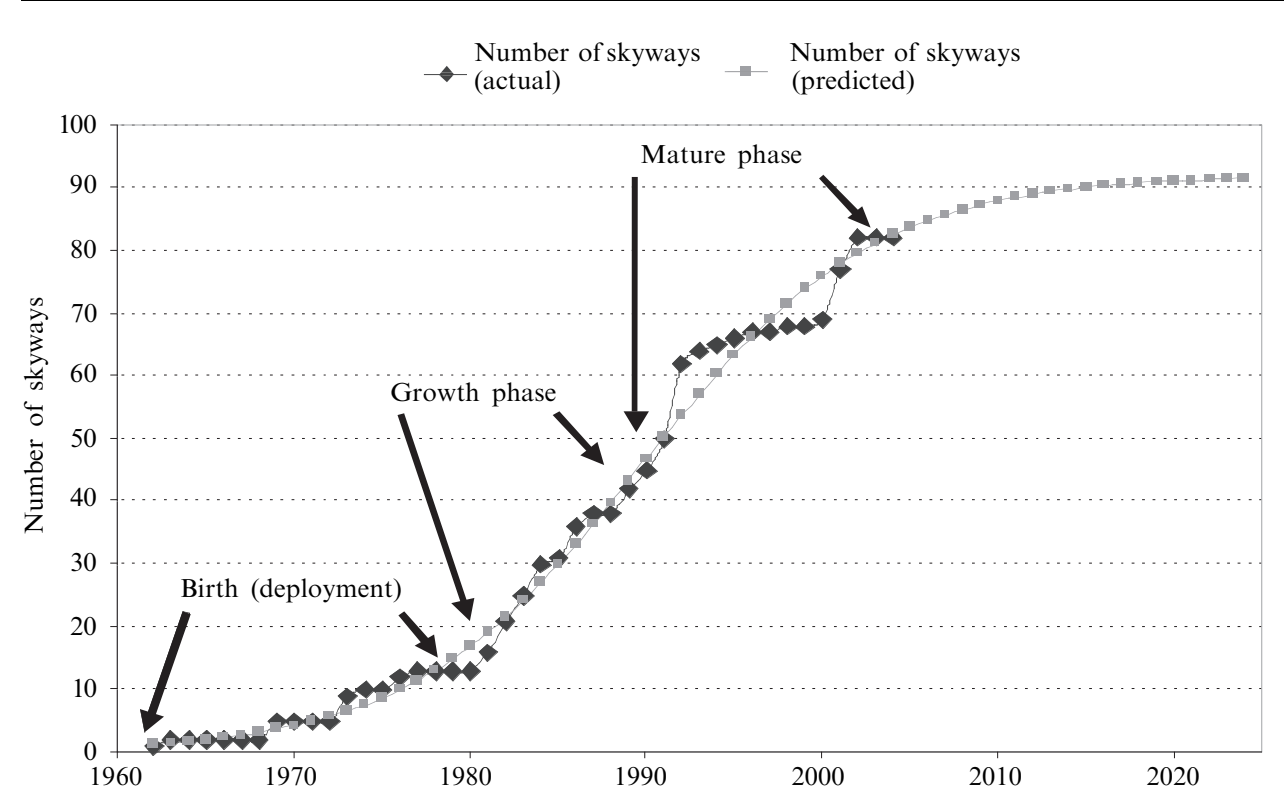

Figure 5. Evolution of the Minneapolis Skyway System over time.

present), as shown on the graph of the cumulative number of skyways built over time (figure 5). The smoothed S-curve in the figure is estimated, following Garrison and Levinson (2005), by fitting a mathematical model that assumes that the data take on a logistic shape. Speculatively extrapolating the S-curve suggests the system will be complete with ninety-two links in 2024. This does not seem unreasonable, as there are not many connections left that can be made in the downtown area without violating the historic building and district policies adopted by the Minneapolis City Council.

\section{Motivation}

The construction of the first skyway in 1962 drew lots of traffic and was deemed a tremendous success. Pedestrian traffic multiplied with the addition of more skyways, as did the number of merchants demanding space along these corridors. The property values of the second level rose, while values in the first-floor held up (Kaufman, 1985). As a result, the overall value of each connected building increased. By the early 1970s retail space on the second level rented for as much as street-level space. Skyway connections were seen as an amenity to a building, thus owners could command higher lease rates for office space.

Throughout the 1980s retail leasing rates steadily climbed, and in some cases were twice the value of some street-level rates (Kaufman, 1985). It soon became conventional wisdom to incorporate skyway connections in architectural plans. Fueled by the desire to add value to their properties, owners and developers had new buildings designed and old ones retrofitted to include skyways.

Urban shopping centers such as City Center and the Conservatory sprung up in the late 1980s and 1990s, and began draining stores from Nicollet Mall. This led some to wonder how much retail space the downtown area could absorb (Robertson, 1994; Whyte, 1988). From a telephone interview with property managers during 5-9 April 2004, we learned that the Conservatory failed and was demolished to make way for a hotel or office and parking complex with some retail. (Some argue that the failure was due to poor design and tenant mix.) 
Donaldson's and Powers department stores left, but were replaced by Saks 5th Avenue and Neiman Marcus, as part of a new Gaviidae Common retail center that expanded over two blocks. According to the telephone interview, Montgomery Wards pulled out of City Center, which is struggling to fill half of its rentable space. Meanwhile, Marshall Fields (Macys), Target, and Block E, all of which are connected by skyways, are reportedly doing quite well. The market for downtown office space is recovering from recession, but vacancy rates are hovering above 20\% (Kramer, 2004).

The office and retail markets are currently in a state of flux, as building owners and retailers adjust to the effects of recent construction and overall lower traffic on the skyway system brought about by the recent recession. ${ }^{(4)}$ Using data from Minnesota Leasing Guide (Kramer, 2004) and from telephone surveys with several property managers, a statistical analysis has been performed to determine how office and retail leasing rates are affected by skyway connections. The main purpose is to test whether or not leasing rates on the skyway level are higher than those on the street level.

Table 1 shows the results of a two-sample $t$-test of the difference of means of office and retail rents on the street and skyway levels. As can be seen, the differences are statistically significant, with higher rents-particularly retail rents, but also office rents - on the skyway level. The collection of higher rent provides a rationale for developers of new buildings adjacent to the skyway system to connect to the network.

Table 1. Rents on the Skyway level and at the street level: two-sample $t$-test assuming equal variances (valid when $n<30$ ).

\begin{tabular}{|c|c|c|c|c|}
\hline & \multicolumn{2}{|l|}{ Offices } & \multicolumn{2}{|l|}{ Retail } \\
\hline & street level & Skyway level & street level & Skyway level \\
\hline Mean & 10.52 & 13.77 & 18.85 & 27.44 \\
\hline Variance & 20.98 & 8.16 & 101.70 & 148.70 \\
\hline Observations & 50 & 50 & 31 & 43 \\
\hline Pooled variance & 19.60 & & 129.10 & \\
\hline Degrees of freedom & 98 & & 72 & \\
\hline$t$-statistic & -3.67 & & -3.21 & \\
\hline $\mathrm{P}\left(T_{i}=t\right)$ one-tail & $1.95 \times 10^{-4}$ & & $9.96 \times 10^{-4}$ & \\
\hline$t$ critical one-tail & 1.66 & & 1.67 & \\
\hline $\mathrm{P}\left(T_{i}=t\right)$ one-tail & $3.91 \times 10^{-4}$ & & $1.99 \times 10^{-3}$ & \\
\hline$t$ critical two-tail & 1.98 & & 1.99 & \\
\hline
\end{tabular}

\section{Accessibility analysis}

To construct a model to perform a point accessibility analysis, the number of job opportunities at each block and the travel times between each of the locations in the skyway system are required.

The number of employees on each block was determined from the floor area of the buildings located there. Current data on floor areas were obtained from Kramer (2004) and the City of Minneapolis and Hennepin County's property finder and information websites. Historic maps and other books dealing with the history of downtown Minneapolis were used to determine which buildings were in place for each of the years the skyway system experienced growth. Gathering data on historic structures proved difficult. The property information websites often did not yield data on structures that are no longer in existence, even if their addresses were provided. 
Old maps usually showed the footprints of buildings, not the floor area or stories. Old photographs and illustrations were sometimes useful for estimating the floor area of buildings, but it was often difficult to estimate how much of the block these structures covered. In the absence of good data, educated guesses were made. In the cases in which data on particular blocks were not available, it was assumed that the blocks contained a collection of 3-5 story buildings which covered approximately $75 \%$ of the block. This translates into $28000 \mathrm{~m}^{2}\left(300000 \mathrm{ft}^{2}\right)$, and is comparable to the current makeup of many of the blocks in the warehouse district of Minneapolis.

Trip generation rates were obtained from the Institute of Transportation Engineers (ITE, 1997). Since most of the land use in downtown Minneapolis was devoted to office and retail, it was not difficult to determine trip generation rates for each block. The ITE trip generation handbook did not have parking ramps listed as a land use, so parking-ramp-occupancy data were obtained from the City of Minneapolis (which owns most of the ramps) in order to estimate trip generation rates.

The website for the City of Minneapolis stated that there were currently 161000 people working in the 3.6 million $\mathrm{m}^{2}$ (39 million $\left.\mathrm{ft}^{2}\right)$ of office and government space in the downtown area. Using these numbers we calculated an average of $22.5 \mathrm{~m}^{2}\left(242 \mathrm{ft}^{2}\right)$ per person, and subsequently used this value to determine the number of employees on each block connected by the skyway system. Whether or not this average held true back to 1962 is debatable, but, owing to a lack of data in this area, it seemed to be the best option.

Determination of the travel times between each of the blocks (all are considered origins and destinations) required several steps. First, a street map of downtown Minneapolis in GIS format was downloaded from the Metropolitan Council's DataFinder website. Using ArcMap, we then manually added the skyways over the street grid. For simplicity, it was assumed that all of the skyway connections were straight paths from the midblock of one building to another. It was also assumed that connections from one block to the next which did not have connecting skyway links (street only), were straight paths from the center of one block to the center of the other. Similarly, links that had the potential to be connected to the skyway system were added as links connecting the center of one block to the center of the next block. Nodes were then created at the center of each linked block (figure 6). The location of each node was determined from the ArcMap coordinates. The length of each link connecting one node to the next was then calculated according to node coordinates.

Accessibility measures the relative ease of reaching valued destinations (Hanson, 1995). To determine if accessibility could be used as a predictor of network growth, the point accessibility of each block lying within and adjacent to the connected system had to be calculated for each time period immediately before the system was expanded. In this paper point accessibility for each of the blocks connected by the skyway system (as well as some unconnected ones) is determined using the following mathematical relation:

$$
A_{i}=T_{i} \sum_{j} T_{j} \mathrm{f}\left(C_{i j}\right)
$$

where $T_{i}$ is some measure of activity at point $i$, in this case the number of jobs or number of trips generated; $T_{j}$ is some measure of activity at point $j$, in this case the number of jobs or number of trips attracted; and $C_{i j}$ is the cost of travel between $i$ and $j$, in this case the travel time by walking.

Note that point accessibility has been calculated separately using two measures of activity, namely the number of jobs and the number of trips, and is used as the input to 


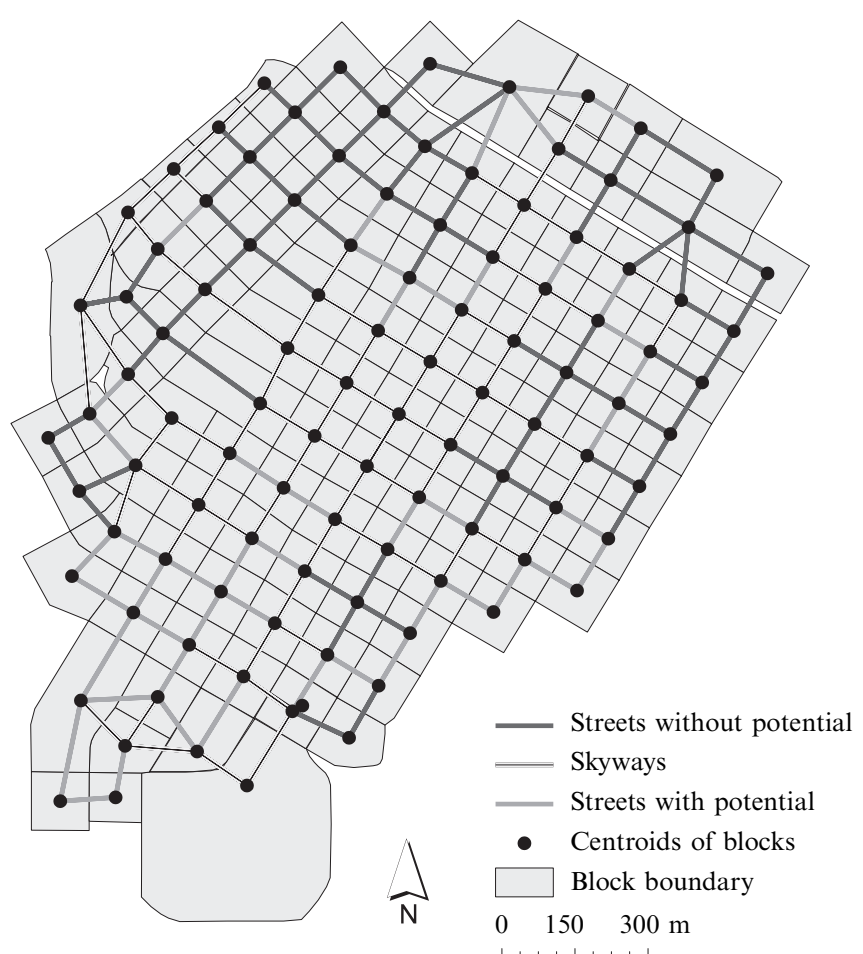

Figure 6. An idealized skyway network in downtown Minneapolis.

the models of network growth explained below. It is not surprising that the models performed better with point accessibility calculated on the basis of trip rates, as the activities that took place on parking ramps will otherwise be ignored, if only the number of jobs is considered. To save space, only results generated on the basis of estimated trip rates are reported in the next sections.

The cost function $\mathrm{f}\left(C_{i j}\right)$ is determined using a gravity model, which states that the cost of traveling from origin $i$ to destination $j$ is inversely related to the square of the distance between them:

$$
\mathrm{f}\left(C_{i j}\right)=\frac{1}{C_{i j}^{2}} .
$$

Calculating the accessibilities of each of the blocks involved several assumptions. The average walking speed was assumed to be $4.8 \mathrm{~km} / \mathrm{hr}$ ( $3.0 \mathrm{miles} / \mathrm{hr})$. However, in the case where travel had to be made from one block to another without using a skyway, the average walking speed was reduced to $2.4 \mathrm{~km} / \mathrm{hr}(1.5 \mathrm{miles} / \mathrm{hr})$. This was done to account for the extra travel time and waiting time to cross streets (especially since most street crossings are made at the ends of blocks, rather than midblock). Thus we essentially assumed that the skyway link between two nodes has half the travel time cost of a nonskyway link. While, to some extent, these assumptions are arbitrary, they are unlikely to affect the accessibility rank of unconnected buildings, since all are treated equally.

With these assumptions, point accessibilities were calculated for each relevant block for each year that the skyway system expanded. Each of the unconnected blocks was ranked in terms of its accessibility value to determine if the most accessible blocks were, in fact, connected first. 


\section{Methodology}

In order to determine how often the expansion connected the blocks with higher accessibility, a connection-choice logit model relating the probability of joining the network (in a given year) to accessibility and network size was employed.

An algorithm was developed to extract potential skyway connections for a given year and to evaluate the impact of building a candidate link on accessibility. It was run for twenty-one iterations, each of which represented a year in which at least one skyway was built, since 1962. Each iteration includes the following steps:

(1) Find all the candidate links for skyway construction, given the network topology in the corresponding year of each iteration. All the links that have not been built as skyways in the year in examination and which do not connect to any restricted blocks are identified as candidates. Only those which are adjacent to established skyways are selected.

(2) Calculate the lowest travel time after improving candidate links one by one. The speed of a candidate link is improved from $2.4 \mathrm{~km} / \mathrm{hr}(1.5 \mathrm{miles} / \mathrm{hr})$ (the speed for nonskyway, or street links) to $4.8 \mathrm{~km} / \mathrm{hr}(3.0 \mathrm{miles} / \mathrm{hr}$ ) (skyway link speed). The travel time between any pair of blocks in the network is recalculated on the basis of the shortest-path-finding algorithm. After the calculation the speed on this link is restored to $2.4 \mathrm{~km} / \mathrm{hr}(1.5 \mathrm{miles} / \mathrm{hr})$, because it is not actually built.

(3) Evaluate the accessibility impact by improving candidate links one by one. On the basis of the recalculated lowest travel time, after building a particular candidate link, the increase in accessibility for both blocks that the candidate link connects to is calculated, as is the increase in accessibility for all the blocks in the network.

(4) Implement the actual skyway connections built. At the end of each iteration the links that were actually in the corresponding year are updated with their improved travel speeds (and thus travel times), and are labeled as ' 1 '. Otherwise if a candidate link was not actually built, it is labeled as ' 0 '.

Consequently, a dataset of 1883 records was created, each record representing a potential skyway connection for a particular year, with a binary variable indicating if the potential connection was actually built in that year. A logit model was then estimated, using the statistical package Stata (Stata Corp LP, College Station, TX), relating the binary variable to corresponding accessibility measures.

Building on the results of the logit model (as explained below in the results section), we developed a network growth simulation model on the basis of the strongest-link assumption, in which one and only one link is constructed per turn, and in which this link is the strongest among all the candidates and provides the highest increase in accessibility for the two blocks it connects. Specifically, this model includes the following four steps, which are similar to those for the connection-choice model except for the last step:

(1) Find all the candidate two-way links for skyway construction.

(2) Calculate the lowest travel time after improving candidate links one by one.

(3) Evaluate the accessibility impact by improving candidate links one by one.

(4) Implement the construction of the 'strongest' candidate, which provides the highest possible increase in accessibility between the two blocks it connects. On each iteration the skyway network is updated with the improved travel speed (and thus travel time) on the strongest link.

The following assumptions are made in implementing the simulation model:

(1) One and only one two-way link is built for each iteration.

(2) The link that is built is the 'strongest link' among eligible candidates in terms of providing the highest additional accessibility for the two connected blocks, if built. 
(3) The eligible candidate links include all the links that were ultimately built as skyways but have not yet been built in the iteration under examination and do not connect to any restricted blocks (ie historic districts, parks).

(4) The simulation starts with one already established link, which is the first skyway, built in 1962. The simulation ends when the candidate pool is exhausted.

(5) In simulation the trip generation rate of each block (building) is estimated by interpolation, according to the number of established links. (For example, if there are twenty-five established links in iteration $k$, and it is known that there were actually twenty-two established links in 1983 and twenty-eight links in 1984, then the trip generation rate of the block is estimated through interpolation, by using the actual trip generation rate of this block in 1983 and that in 1984, according to the number of links.)

The simulation model generated a 'predicted' sequence of skyway link additions, based on the 'strongest-link' assumption. A Spearman's rank-order correlation test was then performed to correlate the predicted sequence of skyway construction in the simulation with the actual sequence in terms of each expansion year observed. Spearman's rank-order correlation test assesses how well an arbitrary monotonic function describes the relationship between two variables - in this case how well two sequences are correlated to each other, without making any assumptions about the frequency distribution of the two sequences (Higgins, 2003).

\section{Results}

The connection-choice logit model results show that the higher the increase in accessibility between the two connected blocks (the access 12 variable) as a result of being connected to the network, the more likely the candidate link will be built (table 2). This is suggested by the sign of the coefficient for the access 12 variable, which is positive and statistically significant. The influence of the accessrest variable (the increase in accessibility of the remaining blocks) is not significant, suggesting that skyway links are generally not built with the goal of improving overall accessibility. This result may be explained by the fact that most of the skyway links are built between private buildings and are paid for privately. Other than the accessibility measures, we have included three explanatory variables: year (indicating the year of skyway construction) and size (denoting the total length of constructed skyways) to eliminate any possible time-trend effect of connection choice-although we realize that year and size may be highly correlated-and $\operatorname{size}^{2}$ (the total length squared), to test if the connection choice has a nonlinear (quadratic) relationship with the total length of the network. As shown in table 2 , though the overall predictive power (as suggested by the pseudo $R^{2}$ of 0.16 ) is

Table 2. Logit model results. $\mathrm{LR}=$ likelihood ratio.

\begin{tabular}{lccrcrc}
\hline Variable & Coefficient & Standard error & \multicolumn{2}{c}{$z$} & $P>|z|$ & $95 \%$ confidence interval \\
\hline access12 & $6.38 \times 10^{-8}$ & $1.37 \times 10^{-8}$ & 4.66 & 0.00 & $3.70 \times 10^{-8}$ & $9.06 \times 10^{-8}$ \\
accessrest & $-2.28 \times 10^{-9}$ & $3.41 \times 10^{-8}$ & -0.07 & 0.95 & $-6.91 \times 10^{-8}$ & $6.45 \times 10^{-8}$ \\
size & $1.56 \times 10^{-4}$ & $2.87 \times 10^{-4}$ & 0.54 & 0.59 & $-4.06 \times 10^{-4}$ & $7.18 \times 10^{-4}$ \\
size $^{2}$ & $-7.87 \times 10^{-9}$ & $1.01 \times 10^{-8}$ & -0.78 & 0.44 & $-2.76 \times 10^{-8}$ & $1.19 \times 10^{-8}$ \\
year & -0.06 & 0.08 & -0.71 & 0.48 & -0.22 & 0.10 \\
const & 113.75 & 164.60 & 0.69 & 0.49 & -208.86 & 436.36
\end{tabular}

Number of observations $=670$

$\operatorname{LR} \chi^{2}(5)=49.29$

Prob $>\chi^{2}=0.00$

Pseudo $R^{2}=0.16$

Log likelihood $=-129.62$ 
relatively low, the logit model reveals that the increase in local accessibility (access12) is a significant predicting factor of network growth. ${ }^{(5)}$

In our previous work we have developed simulation models that represent the dynamics of a surface transportation network, on the basis of myopic local optimality heuristics (Xie and Levinson, 2007; 2008). For instance, Xie and Levinson (2008) simulated the decline of an overinvested surface transportation network by removing the weakest link in the network with the lowest volume of traffic, in an iterative process. The idea arose from the greedy algorithm (Cormen et al, 1990), which makes a locally optimum choice in a discrete optimization process at each stage, with the hope of finding the global optimum. In this case, as the connection-choice logit model disclosed that accessibility is a significant predicting factor of the growth of the skyway network, we accordingly constructed a simulation model predicting the course of incremental network growth on the basis of the strongest-link assumption - namely, that the potential link which provides the highest increase in accessibility for the two blocks which it connects gets constructed. Obviously, the model sacrifices the considerations of specific physical, economic, and regulatory factors that may affect the connection choice in the skyway system. The purpose of proposing this model, though, is to examine to what extent simulation based on myopic local optimality heuristics can reproduce the real course of network expansion.

On the basis of historical land-use data in downtown Minneapolis, the simulation model predicted a sequence of skyway additions from scratch, and this was then compared with the actual sequence, using the Spearman rank-order correlation test, as shown in figure 7. The statistical test shows that there is a significantly strong correlation ( 0.59 ) between the sequence of link construction predicted in the simulation and the real sequence retrieved from historical observation. This demonstrates that the

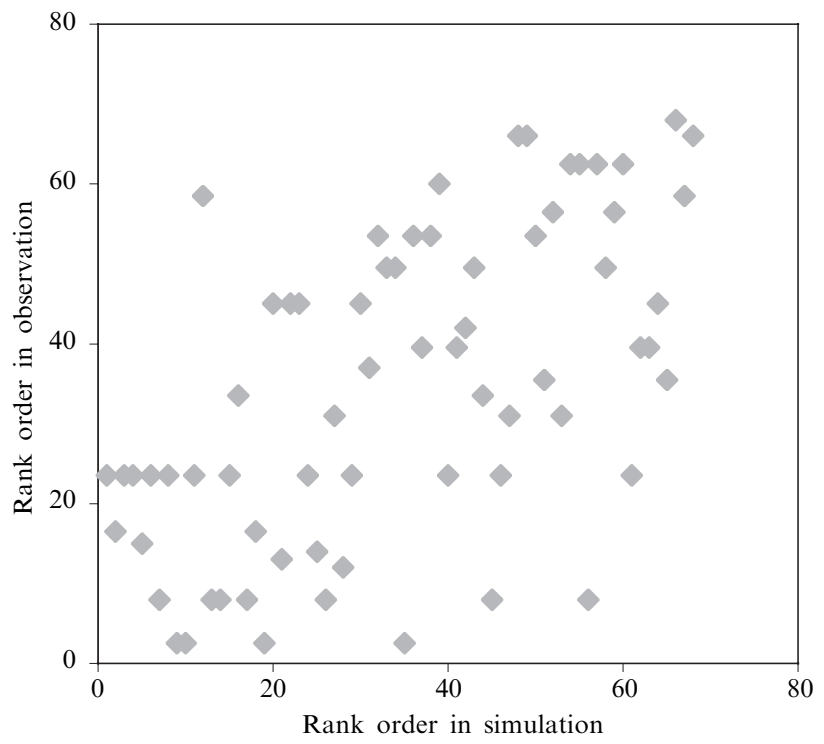

Figure 7. Spearman rank order in observation versus rank order in simulation

(5) The coefficients of size and size $e^{2}$ imply that the probability of constructing a skyway, with other variables controlled, increases (but at a decreasing rate) with the total length of established skyways by the year of examination, while the coefficient of year suggests that the probability decreases as time passes by. As none of the three coefficient estimates turns out to be statistically significant, the inclusion of the three variables in this model will not influence the probability of skyway construction significantly. 
simulation model performs well in predicting the sequence of skyway link construction on the basis of the strongest-link assumption.

In order to examine the robustness of the Spearman rank-order correlation coefficient obtained with the strongest-link hypothesis, an alternative hypothesis was tested in which the next skyway connection is instead randomly drawn from the candidate set. We ran the simulation on the basis of the alternative hypothesis and recalculated the Spearman correlation coefficient, which correlates the sequence of random link additions with the observed sequence. The process was repeated five times with different random seeds, and the results are summarized in table 3. As can be seen, none of the Spearman coefficients from the random link-addition process is statistically significant, thereby showing that a random sequence of link additions is independent from the actual sequence. Using random-connection results as a benchmark, the Spearman coefficient, calculated on the basis of the strongest-link hypothesis, not only shows the right sign, but is also statistically significant. This experiment provides further evidence that accessibility is a significant predictor of link connection choice in the skyway network, and that a simulation based on a myopic strongest-link hypothesis performs well in predicting the sequence of link additions in the network.

Table 3. Spearman rank-order correlation coefficients calculated on the basis of different hypotheses.

Spearman $P$-value

coefficient

\begin{tabular}{lcc}
\hline Strongest-link hypothesis & 0.591 & 0.00 \\
Random-link hypothesis & & \\
random seed 1 & -0.166 & 0.19 \\
random seed 2 & -0.136 & 0.28 \\
random seed 3 & -0.205 & 0.10 \\
random seed 4 & -0.008 & 0.97 \\
random seed 5 & -0.161 & 0.20
\end{tabular}

\section{Conclusions}

In the case of the Minneapolis Skyway System, accessibility is an important factor in predicting which links are connected. The network expanded primarily to the blocks with the highest measure of accessibility in the early stages of development, and in a few cases where buildings were rebuilt in the CBD. Most expansions were linked to blocks with lower accessibilities. A significant number of skyway connections (twenty four) were made to blocks that had potential changes in accessibility values which ranked within the top ten.

A connection-choice logit model relating the probability of joining the network (in a given year) to accessibility corroborates the hypothesis that accessibility is a significant explanatory factor of network growth, although the estimated statistical model is far from determinative. A network growth simulation model was then developed on the basis of the myopic strongest-link assumption (ie only the link that ranked the highest, in terms of increasing accessibility between the two blocks it connects, was constructed). The results show that the simulation model constructed on the basis of the myopic local optimality heuristic (strongest-link assumption) performs well in predicting the sequence of skyway additions, and suggest that, although various physical, economic, regulatory, and legal factors may have played a role, accessibility remains an important factor in predicting the expansion of the Minneapolis Skyway network. 
One reason why the most accessible blocks were not always connected first may have to do with some of the specific physical characteristics of the buildings (ie connection difficulties and lack of logical entry points into the buildings). A number of building owners may also have been averse to the idea of losing rentable office space. More savvy building owners in less accessible locations may have felt that the potential benefits of being connected were substantial, and consequently pushed aggressively to be included in the system. Many of the skyways were connected to parking ramps, which generally had relatively low accessibility values, owing to the fact that most of them are located on the edges of the downtown area. The SAC came into play as a regulator of skyway development after 1980. In addition, politics and redevelopment objectives also played a role-especially in the 1990s, as the city sought to connect the Convention Center to the system (presumably to attract more conventions and bring more convention goers into the retail and restaurant areas) and the Third Avenue parking ramps (to encourage more patronage). This study could be extended in the future to include more sophisticated considerations of ownership, alliance, and conflicting private and public interests during the development of urban transportation networks.

Acknowledgements. This material is based in part upon work by the US National Science Foundation under grant no. 0236396. Any opinions, findings, and conclusions or recommendations expressed in this material are those of the authors and do not necessarily reflect the views of the National Science Foundation. We sincerely thank the anonymous reviewers, who provided insightful comments on the previous version of this manuscript.

\section{References}

Byers J P, 1998 Breaking the Ground Plane: The Evolution of Grade Separated Cities in North America PhD thesis, Department of Geography, University of Minnesota, Minneapolis, MN Cormen T H, Leiserson C E, Rivest R L, Stein C, 1990 Introduction to Algorithms (MIT Press, Cambridge, MA)

Garrison W, Levinson D, 2005 The Transportation Experience: Policy, Planning, and Deployment (Oxford University Press, Oxford)

Hanson S (Ed.), 1995 The Geography of Urban Transportation (Guilford Press, New York)

Higgins J J, 2003 Introduction to Modern Nonparametric Statistics (Brooks/Cole, Pacific Grove, CA)

ITE, 1997 ITE Trip Generation Manual 6th edition, Institute of Transportation Engineers, Washington, DC

Jacob B, 1984 Skyway Typology: A Study of the Minneapolis Skyways (AIA Press, Washington, DC)

Kaufman S, 1985 The Skyway Cities (CSPI, Minneapolis, MN)

Kramer M B, 2004 Minnesota Leasing Guide first quarterly edition (Law Bulletin, Chicago, IL)

Robertson K A, 1994 Pedestrian Malls and Skyways (Ashgate, Aldershot, Hants)

Whyte W H, 1988 City: Rediscovering the Center (Doubleday, New York)

Xie F, Levinson D, 2007, "The weakest link: a model of the decline of surface transportation networks" Transportation Research part E 44100 - 113

Xie F, Levinson D, 2008, "The topological evolution of road networks" Computers, Environment and Urban Systems forthcoming, doi:10.1016/j.compenvurbsys.2008.09.009 
Conditions of use. This article may be downloaded from the E\&P website for personal research by members of subscribing organisations. This PDF may not be placed on any website (or other online distribution system) without permission of the publisher. 